\title{
Isokinetic Strength of Trunk Flexors and Extensors Muscles in Adult Men with and without Nonspecific Back Pain: A Comparative Study
}

\author{
Wael Gabr ${ }^{1,2 *}$, Reda S. Eweda ${ }^{3,4}$ \\ ${ }^{1}$ Neurology Department, Faculty of Medicine, Mansoura University, Mansoura, Egypt \\ ${ }^{2}$ Internal Medicine Department, Faculty of Medicine, Tiabah University, Al-Madinah Al-Munawarah, KSA \\ ${ }^{3}$ Physical Therapy Department for Musculoskeletal Disorders and Its Surgery, Faculty of Physical Therapy, Cairo University, \\ Cairo, Egypt \\ ${ }^{4}$ Faculty of Medical Rehabilitation Sciences, Taibah University, Al-Madinah Al-Munawarah, KSA \\ Email: *waaael@yahoo.com, redaawada@yahoo.com
}

How to cite this paper: Gabr, W. and Eweda, R.S. (2019) Isokinetic Strength of Trunk Flexors and Extensors Muscles in Adult Men with and without Nonspecific Back Pain: A Comparative Study. Journal of Behavioral and Brain Science, 9, 340-350.

https://doi.org/10.4236/jbbs.2019.99025

Received: August 17, 2019

Accepted: September 9, 2019

Published: September 12, 2019

Copyright $\odot 2019$ by author(s) and Scientific Research Publishing Inc. This work is licensed under the Creative Commons Attribution International License (CC BY 4.0).

http://creativecommons.org/licenses/by/4.0/

\begin{abstract}
Background: There is no proven relationship between back pain and trunk muscle strength, researches in this field yielded conflicting results: some found significant weakness of trunk muscles in back pain patients compared with healthy subjects, however many researches did not show any relationship. Objectives: The focus of this study is to assess the trunk muscles strength using isokinetic dynamometer then tries to find a relation between back pain and trunk muscles strength. Materials and Methods: Fifty patients with back pain (BP) and 50 healthy subjects were recruited in this study. The flexors and extensors of the trunk muscles were evaluated by Isokinetic dynamometer and compared with control groups. Results: Patients with acute back pain show a significant reduction of the trunk muscles strengths at $120 \%$ velocities ( $\mathrm{p}$ value $<0.05$ ) with reversed flexor/extensor ration in comparison with sound subjects. Such a relationship does not show in subacute or chronic back pain patients. Conclusions: Acute back pain associated with decreased the strength of the trunk flexors and extensors at $120 \%$ s. The trunk muscle reinforcement programs must be considered in-patients with acute back pain.
\end{abstract}

\section{Keywords}

Back Pain, Trunk Muscles, Isokinetic, Spine, Torque 


\section{Introduction}

Low back pain is a major health problem worldwide, affecting all ages and different socioeconomic standers [1]. It is more prevalent in developing countries [2]. About two third of the general population worldwide report at least one attack of low back pain in their life and more than half of them have relapses of pain later on [3]. The prevalence of back pain varies from $12 \%$ to $38 \%$ in different races [1] [4].

When the pathology of low back pain is identified, the condition known as specific low back pain, while when the pathology can't be identified the condition known as non-specific low back pain [5] [6].

The exact causes of low back pain disorders are not known in many cases [7] [8] [9]. Actually it is a multi-factorial problem. It has a patho-anatomical aspects, psychological factors, social base, neuro-physiological and physical aspects. The treatment of this condition may be difficult [10] [11], so the management is usually empirical [7].

Weakness of trunk muscles has been pointed out as causes, consequences or influencing factors for the back pain [12] [13] [14]. It has been proposed that back muscles secure the underlying spine from excessive bending [15]. Some studies detect an associated between the episodes of BP and decreased truck muscle strength [14] [16] [17]. Some studies attributed this to the endurance of the trunk extensor muscles [18] [19] [20]. However, other researchers failed to find any correlations between trunk muscles strength and back pain [21]. So the exact relation between trunk muscles strength and back pain occurrence need to be investigated. Trunk muscles strength cannot be accurately examined with conventional methods [22]. The isokinetic dynamometer provides correct assessment of muscle function and can be used to study the exact relationship between the back pain and trunk muscles [23].

The aim of the present study was to check and compare the muscle torque and power velocity of the trunk muscles in healthy men and male patients with low back pain to detect the relationship between low back pain and trunk muscles strength in absence of structural neurological lesions.

\section{Materials and Methods}

This study was conducted according to the guidance of 1995 of Helsinki and was approved by the Ethical Committee of college of medical rehabilitation sciences, Taibah University. Informed written consent was obtained from all participants' subjects. All patients with non-specific low back pain revised Taibah university medical unit for men during the period from October 2016 to May 2018 and accepted to be enrolled in this study was included after obtaining informed written consent.

The study enrolled 50 male patients with low back pain (patient group) they had a mean age of $22.9 \pm 3.4$ years (range from 20 to 42 years) and 50 healthy men (control group) they had a mean age of $23.4 \pm 3.9$ (range from 20 to 40 
years), The patients enrolled in this study, had body mass index (BMI) $26.6 \pm$ 6.6 , with back pain duration ranging from 8 to 270 days (78.7 \pm 77.4$)$. All patients were men as this clinic serve men only.

Back pain is defined as pain and discomfort, that occurs lower to the costal margin and superior to the inferior gluteal folds, it may be associated with referred leg pain [3]. According to back pain duration, it is divided into acute back pain which lasts for less than one month, subacute BP lasts from 4 to 12 weeks, while, chronic BP lasts more than three months [11] [24].

Back pain is classified into two different subtypes: "Specific back pain", which has a recognizable pathology and "non-specific back pain", which can't be attributed to a recognizable pathology. All patients do X-ray for lumbosacral spine to exclude any severe degenerative arthritis, local infection, tumors, osteoporosis, structural deformity, lumbosacral fracture, radicular syndrome or cauda equina syndrome. MRI lumbosacral was done in any cases with suspected neurological deficit.

Patients with the earlier history of spinal surgery intervention, whiplash injury, clear neurological deficit on examination, X-ray evidence of severe degenerative arthritis, diagnosis of fibromyalgia or history of physical therapy during the last one year were excluded. On clinical examination if any neurological deficit was detected, MRI was performed.

Participants completed a questionnaire about the pack pain, as following: "Have you ever had pain in the region of the back?" (yes or no); "Mention the days of your back pain?" "Did you suffer from this back pain in the past month?" (yes or no); "Have you ever had back pain for more than 3 months?" (yes or no); "Have you ever suffer from neck pain?" (yes or no); "Have you ever had limb pain with your backache?” (yes or no), followed by complete medical history taking. A physical and full neurological assessment of the participant was carried out after the questionnaire. All tests were carried out by one neurologist [25]. The modified Oswestry low back pain disability questionnaire was used to detect the degree of patient disabilities [26].

With shoes removed, height (meter) was measured, body weight (kg) was measured and body mass index was calculated.

The studied groups were evaluated using an Isokinetic strength of the trunk extensor and flexor muscles using multi-joint system Isokinetic Dynamometer System 4 Pro (biodex system 4 pro, biodex medical inc, Shirley, NY, USA), with Patient Positioning System including motorized seat height, front-to-back chair adjustment, fully assisted dynamometer height adjustment, and side-to-side adjustment with touch screen interface for quick, easy multi-mode operation; isokinetic, isometric and isotonic modes. The device was calibrated before each assessment session.

The isokinetic strength test is utilized broadly to quantitatively evaluate muscle strength through estimation of the torque of the muscle during movement of a joint at a constant angular velocity [27] [28]. Back muscles performance was tested by using Biodex dual position extension/flexion back test from semi 
standing position which allows the patient full trunk range of motion with isolated lumbar position for clinical testing of the back.

Trunk muscles strength can be evaluated in different velocities ranging between 30 and $180^{\circ} \%$ s. No definite velocity has upper hand than the other [29]. We used 60 and $120^{\circ} / \mathrm{s}$, which is the most commonly used to test trunk flexors and extensors muscles strength.

The same operator performs all isokinetic tests to prevent assessment verifiability. The first step in the examination was to instruct the examined individual about how the test will be done with proper explanation and illustration of the test procedures, the subject then placed on the isokinetic dynamometer in semi-standing position while both feet were supported in foot support. Both thighs and back were fixed to the chair by a strap, and making the patient hold the handle placed near the front chest to prevent motion of the upper limb and hip joint [29]. If movement of either the upper limbs or hip joints were observed, that data was excluded. The axis of the dynamometer was placed on the patient's anterior superior iliac spine. The range of motion of the arm was adjusted for each patient according to the patient's maximal flexion and extension. First, all patients were instructed to flex and extend the back with the greatest effort at an angular velocity of $60 \% \mathrm{sec}$, Interval, then patients were instructed to execute flexion and extension of the back with the greatest effort at an angular velocity of $120 \% \mathrm{sec}$. For each examined individual the peak torques for the flexor and extensor muscles were determined, At least two minute of rest was lapsed between 2 preset-velocity trials. Only the highest peak torque was used for the data analysis. The flexors to extensor ratio were calculated, and also the average power of the trunk flexor and extensor muscles were determined. All subjects in this study completed the isokynetic tests without any complaints; the tests were tolerable in all patients.

The intensity of the low back pain evaluated on a 0 to 10 visual analogue scale (VAS), then the pain is categorized into mild (VAS 1-4), moderate (VAS 5-6) and severe (VAS 7-10) [30].

\section{Statistical Analysis}

Data entry and analysis was performed using IBM SPSS Statistics for Windows, Version 20.0. Armonk, NY: IBM Corp, 2011. Independent samples t-test was performed to compare the differences between the participants with and without back pain. The differences in age, BMI, peak torque for trunk flexors and extensors as well as average power between subjects with BP and control group was calculated. The statistical significance level was fixed at 0.05 .

\section{Results}

Demographic data for patients and controls groups are shown in Table 1, which shows no statistical difference in age, weight, height or BMI. The disease duration was $78.7 \pm 77.4$ days among patients group ranging from 8 to 270 days. The pain severity ranging from 1 to 9 the mean was $4.0 \pm 1.5$. All studied subjects 
were men as the clinic is specific to serve men only (Table 1).

Table 2 shows a significant difference between healthy controls and back pain participants as regard the mean peak torque values for the trunk flexor and extensor muscles at $60 \% \mathrm{~s}$ and $120 \%$ s, not only the patient group shows a weaker flexor and extensor trunk muscles but also shows that the flexor/extensor ratio was reversed at $120^{\circ} / \mathrm{s}$ (greater than 1), while; There were no statistical significant differences between the mean peak torque values for the trunk flexor and extensor muscles of the patients when compared with the control group at $60 \%$ and the flexor/extensor ratio was preserved.

The mean average power for the trunk flexor and extensor muscles did not detect a significant difference between the studied groups; these results are summarized in Table 2.

When the patient further divided into acute, subacute and chronic then compared with the control group, there were statistically significant differences between the mean peak torque values for the trunk flexor and extensor muscles of the patients with acute back pain, while; subacute and chronic patient failed to show a significant correlation compared to the control group.

Only the mean Average power for the trunk flexor and extensor muscles of the patient with acute back pain showed statistically significant differences when compared to the controls while patients with subacute and chronic low back pain failed to show a significant difference (Table 3 ).

Table 1. Demographic data of the studied groups.

\begin{tabular}{|c|c|c|c|c|c|c|c|}
\hline & \multicolumn{3}{|c|}{ Patient } & \multicolumn{3}{|c|}{ Control } & \\
\hline & Minimum & Maximum & $($ Mean $\pm \mathrm{SD})$ & Minimum & Maximum & $($ Mean $\pm \mathrm{SD})$ & $\mathrm{p}$ Value \\
\hline Age (Years) & 20 & 42 & $22.9 \pm 3.4$ & 20 & 40 & $23.4 \pm 3.9$ & 0.58 \\
\hline Height $(\mathrm{cm})$ & 154 & 182 & $170.6 \pm 6.4$ & 156 & 190 & $170.6 \pm 7.9$ & 0.99 \\
\hline Weight (kg) & 46 & 150 & $77.7 \pm 21.1$ & 50 & 115 & $76.1 \pm 15.5$ & 0.67 \\
\hline BMI & 17 & 48 & $26.6 \pm 6.6$ & 19 & 36 & $26.1 \pm 4.7$ & 0.70 \\
\hline $\begin{array}{l}\text { Duration } \\
\text { (Months) }\end{array}$ & 8 & 270 & $78.7 \pm 77.4$ & 0 & 0 & $0.0 \pm 0.0$ & \\
\hline Pain Severity & 1 & 9 & $4.0 \pm 1.5$ & 0 & 0 & $0.0 \pm 0.0$ & \\
\hline Disability & 3 & 17 & $7.7 \pm 3.3$ & 0 & 0 & $0.0 \pm 0.0$ & \\
\hline
\end{tabular}

The subjects are expressed in means \pm standard deviation.

Table 2. The trunk extensors and flexors muscles at $60 \% \mathrm{sec}$ and $120 \% \mathrm{sec}$ in studied groups.

\begin{tabular}{ccccccc}
\hline & \multicolumn{2}{c}{$60^{\circ} / \mathrm{sec}$} & \multicolumn{3}{c}{$120^{\circ} / \mathrm{sec}$} \\
\hline & Patients & Controls & p Value & Patients & Controls & p Value \\
\hline Extension Peak Torque & $128.8 \pm 73.3$ & $117.9 \pm 58.2$ & 0.06 & $98.6 \pm 56.0$ & $125.5 \pm 68.1$ & $0.03^{*}$ \\
Flexion Peak Torque & $106.0 \pm 40.4$ & $118.7 \pm 37.1$ & 0.10 & $102.1 \pm 39.8$ & $121.1 \pm 39.7$ & $0.02^{\star}$ \\
Extension Average Power & $63.0 \pm 45.5$ & $68.4 \pm 47.6$ & 0.57 & $56.6 \pm 56.9$ & $61.7 \pm 59.0$ & 0.66 \\
Flexion Average Power & $54.0 \pm 24.7$ & $56.0 \pm 25.2$ & 0.69 & $45.7 \pm 31.4$ & $57.7 \pm 36.5$ & 0.08 \\
\hline
\end{tabular}

The subjects are expressed in means \pm standard deviation., ${ }^{*}=$ statistically significant relation $\mathrm{p}<0.05$. 
Table 3. The trunk extensors and flexors muscles at $60 \% \mathrm{sec}$ and $120^{\circ} / \mathrm{sec}$ in patients' subgroups.

\begin{tabular}{cccccccc}
\hline & Control & Acute & $\mathrm{p}$ Value & Suacute & $\mathrm{p}$ Value & Chronic & $\mathrm{p}$ Value \\
\hline $\begin{array}{c}\text { Extension Peak } \\
\text { Torque at 60 }\end{array}$ & $141.0 \pm 64.5$ & $91.5 \pm 57.1$ & $0.003^{*}$ & $133.1 \pm 61.7$ & 0.96 & $137.7 \pm 45.7$ & 0.58 \\
$\begin{array}{c}\text { Extension Peak } \\
\text { Torque at 120 }\end{array}$ & $125.5 \pm 68.1$ & $69.2 \pm 49.6$ & $0.000^{*}$ & $112.3 \pm 49.0$ & 0.42 & $123.5 \pm 55.2$ & 0.91 \\
$\begin{array}{c}\text { Flexion Peak } \\
\text { Torque at 60 }\end{array}$ & $118.7 \pm 37.1$ & $89.7 \pm 34.5$ & $0.004^{*}$ & $116.9 \pm 48.1$ & 0.90 & $116.9 \pm 35.0$ & 0.86 \\
$\begin{array}{c}\text { Flexion Peak } \\
\text { Torque at 120 }\end{array}$ & $121.1 \pm 39.7$ & $81.5 \pm 34.9$ & $0.000^{*}$ & $113.7 \pm 41.3$ & 0.56 & $117.7 \pm 34.5$ & 0.75 \\
$\begin{array}{c}\text { Avarage Power } \\
\text { (Extension) 60 }\end{array}$ & $68.4 \pm 47.6$ & $41.8 \pm 35.2$ & $0.014^{*}$ & $71.0 \pm 51.2$ & 0.86 & $82.4 \pm 43.0$ & 0.28 \\
$\begin{array}{c}\text { Average Power } \\
\text { (Extension) 120 }\end{array}$ & $61.7 \pm 59.0$ & $37.6 \pm 37.1$ & $0.045^{*}$ & $65.1 \pm 57.5$ & 0.85 & $72.8 \pm 71.6$ & 0.58 \\
$\begin{array}{c}\text { Average Power } \\
\text { (Flexion) 60 }\end{array}$ & $56.0 \pm 25.2$ & $38.9 \pm 19.7$ & $0.004^{*}$ & $71.5 \pm 25.7$ & 0.06 & $57.6 \pm 18.1$ & 0.78 \\
$\begin{array}{c}\text { Average Power } \\
\text { (Flexion) 120 }\end{array}$ & $57.7 \pm 36.5$ & $32.0 \pm 24.9$ & $0.001^{*}$ & $61.3 \pm 35.5$ & 0.75 & $49.2 \pm 29.2$ & 0.35 \\
\hline
\end{tabular}

The subjects are expressed in means \pm standard deviation, ${ }^{*} \mathrm{p}<0.05=$ statistical significant difference between the patients' subgroups compared to controls.

\section{Discussion}

Many researches were performed on trunk muscle strength in patients with back pain to get a conclusive relationship between trunk muscle performance and back pain, but till now no reliable opinion was reached. Some studies found that the trunk muscles were weaker in patients with back pain [14] [31] [32] [33]. Other studies failed to confirm a clear relationship between trunk muscles and back pain [34] [35].

The primary focus of this study was to find and check the relationship between back pain among men and the strength of trunk muscles using the isokinetic dynamometer, as trunk muscles support the spine and keep up its stability, so weakness of these muscles leads to increase stress on lumbar vertebra and production of non-specific back pain.

Our study found significant reduction of the trunk muscles strength in acute back pain patient at $120 \%$ velocities with reversed flexor extensor ration in comparison with healthy subjects, but failed to find that relation in patient with subacute or chronic back pain, this was in a harmony with the research of Pope and his colleagues (1985), who found that Patients with low back pain had weaker trunk flexor and extensor and the trunk flexor muscles were overpowered [36], but the author didn't clarify the relation between this weakness and the low back pain subtypes, also study conducted by Mayer and his colleagues (1985), found that trunk extensors were more affected than flexors in back pain patients [37]. A later research done by Cho and his colleagues (2014), found that the incidence of back pain correlated to isometric and isokinetic trunk extensor weakness, while the severity of back pain correlated to isometric and isokinetic 
trunk extensor and flexor weakness [33].

In the contradictory an earlier research by Merati and his colleagues (2004) on children with and without back pain, no significant differences in trunk muscular performance among children with back pain compared with those without back pain and they suggested that the isokinetic and isometric back muscles strengths are not directly correlated to back pain occurrence [35]. Bernard and his colleagues (2012) reported no significant difference in the isokinetic trunk strength of both flexors and extensors in back pain and control groups [34].

The normal flexor/extensor ratio ensures that the flexor muscles produce enough contraction to decelerate the extensor muscles during trunk movements preventing ligaments and muscles injuries during violent or daily activities [38] [39] [40] [41]. Therefore, flexor/extensor imbalances have been tested as possible cause of BP [12] [42] [43].

Previous research on trunk muscle strength by Suzuki and his colleagues (1995), not found any difference in trunk flexion/extension strength ratio between BP patients and healthy participants [43]. The same conclusion reached by Ripamonti and his colleagues (2009), suggested that persons experiencing back pain show a normal flexor/extensor ratio, and thus the flexor/extensor ratio can't be considered as a predictive factor in patients with back pain [29]. In contrast our results show a reversed flexor/extensor ratio at $120 \%$ among patients group, this means that trunk extension movements may result in more prominent trunk flexion strength than extension, resulting in a trunk strength imbalance. Yet, results within our study show similarities with findings from Shirado and his colleagues who also found greater trunk flexor/extensor ratios in patients with BP compared to non-BP subjects [42]. Likewise, Lee and his colleagues, revealed a significant difference in the trunk flexor/extensor ratio between the healthy subjects and the BP sufferers [14].

Within this study, there are certain limitations that can be addressed. First, the sample size of both back and healthy controls only reached 50 participants for each group, which resulted in insufficient statistical power to conclude any evidence from the results of this study. Secondly, included participants were only men who have better musculature compared to women. Further studies were needed on both men and women and on larger scale to get a clearer vision on this point of research.

\section{Conclusion}

Acute back pain associated with decreased the strength of the trunk flexors and extensors at $120 \%$. The trunk muscle reinforcement programs must be considered in patient with acute back pain.

\section{Ethics Approval and Consent to Participate}

The study protocol was approved by the ethical committee in Taibah University, AL Madinah, KSA, on April 2016. Participation was voluntary and all contribu- 
tors or their first-degree relatives received detailed information about the aims of this research work and an informed written consent to participate was obtained prior to the commencement of the study.

\section{Availability of Data and Materials}

All raw data will be available on the editor request.

\section{Funding}

This research did not receive any grant from funding agencies in the public, commercial, or not-for-profit sectors.

\section{Authors' Contributions}

This work was carried out by two authors WG, and RA. WG designed the study, reviewed literature, and wrote the primary draft of the manuscript, RA collected the data, performed statistical analysis. Both authors read and approved the final manuscript.

\section{Acknowledgements}

We wish to express our great appreciation to our patients and their family for supporting us during this work.

\section{Conflicts of Interest}

The authors declare no conflicts of interest regarding the publication of this paper.

\section{References}

[1] Hoy, D., Bain, C., Williams, G., March, L., Brooks, P., Blyth, F., et al. (2012) A Systematic Review of the Global Prevalence of Low Back Pain. Arthritis \& Rheumatology, 64, 2028-2037. https://doi.org/10.1002/art.34347

[2] Volinn, E. (1997) The Epidemiology of Low Back Pain in the Rest of the World. Spine, 22, 1798. https://doi.org/10.1097/00007632-199708010-00023

[3] Airaksinen, O., Brox, J.I., Cedraschi, C., Hildebrandt, J., Klaber-Moffett, J., Kovacs, F., et al. (2006) Chapter 4 European Guidelines for the Management of Chronic Non-Specific Low Back Pain. European Spine Journal, 15, s192-s300. https://doi.org/10.1007/s00586-006-1072-1

[4] Omokhodion, F.O. and Sanya, A.O. (2003) Risk Factors for Low Back Pain among Office Workers in Ibadan, Southwest Nigeria. Occupational Medicine, 53, 287-289. https://doi.org/10.1093/occmed/kgg063

[5] Balague, F., Mannion, A.F., Pellise, F. and Cedraschi, C. (2012) Non-Specific Low Back Pain. The Lancet, 379, 482-491. https://doi.org/10.1016/S0140-6736(11)60610-7

[6] Kent, P.M. and Keating, J.L. (2005) The Epidemiology of Low Back Pain in Primary Care. Chiropractic \& Osteopathy, 13, Article No. 13. https://doi.org/10.1186/1746-1340-13-13

[7] O’Sullivan, P. (2005) Diagnosis and Classification of Chronic Low Back Pain Dis- 
orders: Maladaptive Movement and Motor Control Impairments as Underlying Mechanism. Manual Therapy, 10, 242-255. https://doi.org/10.1016/j.math.2005.07.001

[8] McCarberg, B.H., Ruoff, G.E., Tenzer-Iglesias, P. and Weil, A.J. (2011) Diagnosis and Treatment of Low-Back Pain Because of Paraspinous Muscle Spasm: A Physician Roundtable. Pain Medicine, 12, S119-S127. https://doi.org/10.1111/j.1526-4637.2011.01253.x

[9] Suzuki, H., Kanchiku, T., Imajo, Y., Yoshida, Y., Nishida, N. and Taguchi, T. (2016) Diagnosis and Characters of Non-Specific Low Back Pain in Japan: The Yamaguchi Low Back Pain Study. PLoS ONE, 11, e0160454. https://doi.org/10.1371/journal.pone.0160454

[10] Maher, C., Underwood, M. and Buchbinder, R. (2017) Non-Specific Low Back Pain. The Lancet, 389, 736-747. https://doi.org/10.1016/S0140-6736(16)30970-9

[11] Qaseem, A., Wilt, T.J., McLean, R.M. and Forciea, M. (2017) Non-Invasive Treatments for Acute, Subacute, and Chronic Low Back Pain: A Clinical Practice Guideline from the American College of Physicians. Annals of Internal Medicine, 166, 514-530. https://doi.org/10.7326/M16-2367

[12] Bayramoglu, M., Akman, M.N., Kilinc, S., Cetin, N., Yavuz, N. and Ozker, R. (2001) Isokinetic Measurement of Trunk Muscle Strength in Women with Chronic Low-Back Pain. American Journal of Physical Medicine \& Rehabilitation, 80, 650-655. https://doi.org/10.1097/00002060-200109000-00004

[13] Grosdent, S., Demoulin, C., Souchet, M., Tomasella, M., Crielaard, J.M. and Vanderthommen, M. (2015) Trunk Muscle Profile in Elite Tennis Players with and without Low Back Pain. The Journal of Sports Medicine and Physical Fitness, 55, 1354-1362.

[14] Lee, J.H., Hoshino, Y., Nakamura, K., Kariya, Y., Saita, K. and Ito, K. (1999) Trunk Muscle Weakness as a Risk Factor for Low Back Pain. A 5-Year Prospective Study. Spine, 24, 54-57. https://doi.org/10.1097/00007632-199901010-00013

[15] Adams, M.A. and Dolan, P. (1991) A Technique for Quantifying the Bending Moment Acting on the Lumbar Spine in Vivo. Journal of Biomechanics, 24, 117-126. https://doi.org/10.1016/0021-9290(91)90356-R

[16] Victora Ruas, C. and Vieira, A. (2017) Do Muscle Strength Imbalances and Low Flexibility Levels Lead to Low Back Pain? A Brief Review. Journal of Functional Morphology and Kinesiology, 2, 29. https://doi.org/10.3390/jfmk2030029

[17] Salminen, J.J., Oksanen, A., Maki, P., Pentti, J. and Kujala, U.M. (1993) Leisure Time Physical Activity in the Young. Correlation with Low-Back Pain, Spinal Mobility and Trunk Muscle Strength in 15-Year-Old School Children. International Journal of Sports Medicine, 14, 406-410. https://doi.org/10.1055/s-2007-1021200

[18] Sjolie, A.N. and Ljunggren, A.E. (2001) The Significance of High Lumbar Mobility and Low Lumbar Strength for Current and Future Low Back Pain in Adolescents. Spine, 26, 2629-2636. https://doi.org/10.1097/00007632-200112010-00019

[19] Bo, A.L., Wedderkopp, N. and Leboeuf-Yde, C. (2006) Association between Back Pain and Physical Fitness in Adolescents. Spine, 31, 1740-1744. https://doi.org/10.1097/01.brs.0000224186.68017.e0

[20] Jones, M.A., Stratton, G., Reilly, T. and Unnithan, V.B. (2005) Biological Risk Indicators for Recurrent Non-Specific Low Back Pain in Adolescents. British Journal of Sports Medicine, 39, 137. https://doi.org/10.1136/bjsm.2003.009951

[21] Balagu, F., Damidot, P., Nordin, M., Parnianpour, M. and Waldburger, M. (1993) Cross-Sectional Study of the Isokinetic Muscle Trunk Strength among School Chil- 
dren. Spine, 18, 1199-1205. https://doi.org/10.1097/00007632-199307000-00013

[22] Calmels, P., Jacob, J.F., Fayolle-Minon, I., Charles, C., Bouchet, J.P., Rimaud, D., et al. (2004) Use of Isokinetic Techniques vs Standard Physiotherapy in Patients with Chronic Low Back Pain. Preliminary Results. Annales de Réadaptation et de Médecine Physique, 47, 20-27. https://doi.org/10.1016/j.annrmp.2003.07.001

[23] Kannus, P. (1994) Isokinetic Evaluation of Muscular Performance: Implications for Muscle Testing and Rehabilitation. International Journal of Sports Medicine, 15, S11-S18. https://doi.org/10.1055/s-2007-1021104

[24] Gleeson, N.P. and Mercer, T.H. (1996) The Utility of Isokinetic Dynamometry in the Assessment of Human Muscle Function. Sports Medicine, 21, 18-34. https://doi.org/10.2165/00007256-199621010-00003

[25] Bindra, S., Sinha, A.G. and Benjamin, A.I. (2013) Questionnaire for Low Back Pain in the Garment Industry Workers. Indian Journal of Occupational and Environmental Medicine, 17, 48-57. https://doi.org/10.4103/0019-5278.123162

[26] Fritz, J.M. and Irrgang, J.J. (2001) A Comparison of a Modified Oswestry Low Back Pain Disability Questionnaire and the Quebec Back Pain Disability Scale. Physical Therapy, 81, 776-788. https://doi.org/10.1093/ptj/81.2.776

[27] Karatas, G.K., Ggs, F. and Meray, J. (2002) Reliability of Isokinetic Trunk Muscle Strength Measurement. American Journal of Physical Medicine \& Rehabilitation, 81, 79-85. https://doi.org/10.1097/00002060-200202000-00001

[28] Thistle, H.G., Hislop, H.J., Moffroid, M. and Lowman, E.W. (1967) Isokinetic Contraction: A New Concept of Resistive Exercise. Archives of Physical Medicine and Rehabilitation, 48, 279-282.

[29] Ripamonti, M., Colin, D., Schmidt, D., Ritz, M. and Rahmani, A. (2009) Isokinetic Evaluation of Trunk Muscles in Healthy and Low Back Pain Subjects. Computer Methods in Biomechanics and Biomedical Engineering, 12, 215-216. https://doi.org/10.1080/10255840903093482

[30] Jensen, M.P., Smith, D.G., Ehde, D.M. and Robinsin, L.R. (2001) Pain Site and the Effects of Amputation Pain: Further Clarification of the Meaning of Mild, Moderate, and Severe Pain. Pain, 91, 317-322. https://doi.org/10.1016/S0304-3959(00)00459-0

[31] Ikeda, Y., Kawai, S., Oda, H., Nomura, K., Fuchigami, Y., Toyoda, K., et al. (1994) Isokinetic Evaluation of Trunk Muscles Using Kin-Corn 3 in Normal Subjects and Patients with Lumbar Spine Disease. Orthopedics \& Traumatology, 43, 1243-1246. https://doi.org/10.5035/nishiseisai.43.1243

[32] Rossi, D.M., Morcelli, M.H., Cardozo, A.C., Denadai, B.S., Gonalves, M. and Navega, M.T. (2017) Rate of Force Development and Muscle Activation of Trunk Muscles in Women with and without Low Back Pain: A Case-Control Study. Physical Therapy in Sport, 26, 41-48. https://doi.org/10.1016/j.ptsp.2016.12.007

[33] Cho, K.H., Beom, J.W., Lee, T.S., Lim, J.H., Lee, T.H. and Yuk, J.H. (2014) Trunk Muscles Strength as a Risk Factor for Nonspecific Low Back Pain: A Pilot Study. Annals of Rehabilitation Medicine, 38, 234-240. https://doi.org/10.5535/arm.2014.38.2.234

[34] Bernard, J.C., Pujol, A., Boudokhane, S., Deceuninck, J. and Chaleat-Valayer, E. (2012) Isokinetic Trunk Strength in the Teenagers with and without Low-Back Pain: A Comparative Study. Scoliosis, 7, O38. https://doi.org/10.1186/1748-7161-7-S1-O38

[35] Merati, G., Negrini, S., Carabalona, R., Margonato, V. and Veicsteinas, A. (2004) Trunk Muscular Strength in Pre-Pubertal Children with and without Back Pain. 
Pediatric Rehabilitation, 7, 97-103. https://doi.org/10.1080/13638490310001654754

[36] Pope, M.H., Bevins, T., Wilder, D.G. and Frymoyer, J.W. (1985) The Relationship between Anthropometric, Postural, Muscular, and Mobility Characteristics of Males Ages 18-55. Spine, 10, 644-648. https://doi.org/10.1097/00007632-198509000-00009

[37] Mayer, T.G., Smith, S.S., Keeley, J. and Mooney, V. (1985) Quantification of Lumbar Function. Part 2: Sagittal Plane Trunk Strength in Chronic Low-Back Pain Patients. Spine, 10, 765-772. https://doi.org/10.1097/00007632-198510000-00012

[38] Croisier, J.L., Forthomme, B., Namurois, M.H., Vanderthommen, M. and Crielaard, J.M. (2002) Hamstring Muscle Strain Recurrence and Strength Performance Disorders. The American Journal of Sports Medicine, 30, 199-203. https://doi.org/10.1177/03635465020300020901

[39] Croisier, J.L., Ganteaume, S., Binet, J., Genty, M. and Ferret, J.M. (2008) Strength Imbalances and Prevention of Hamstring Injury in Professional Soccer Players: A Prospective Study. The American Journal of Sports Medicine, 36, 1469-1475. https://doi.org/10.1177/0363546508316764

[40] Ruas, C.V., Minozzo, F., Pinto, M.D., Brown, L.E. and Pinto, R.S. (2015) LowerExtremity Strength Ratios of Professional Soccer Players According to Field Position. The Journal of Strength \& Conditioning Research, 29, 1220-1226. https://doi.org/10.1519/JSC.0000000000000766

[41] Ruas, C.V., Brown, L.E., Lima, C.D., Costa, P.B. and Pinto, R.S. (2018) Effect of Three Different Muscle Action Training Protocols on Knee Strength Ratios and Performance. The Journal of Strength \& Conditioning Research, 32, 2154-2165. https://doi.org/10.1519/JSC.0000000000002134

[42] Shirado, O., Ito, T., Kaneda, K. and Strax, T.E. (1995) Concentric and Eccentric Strength of Trunk Muscles: Influence of Test Postures on Strength and Characteristics of Patients with Chronic Low-Back Pain. Archives of Physical Medicine and Rehabilitation, 76, 604-611. https://doi.org/10.1016/S0003-9993(95)80628-8

[43] Suzuki, N. and Endo, S. (1983) A Quantitative Study of Trunk Muscle Strength and Fatigability in the Low-Back-Pain Syndrome. Spine, 8, 69-74.

https://doi.org/10.1097/00007632-198301000-00012 